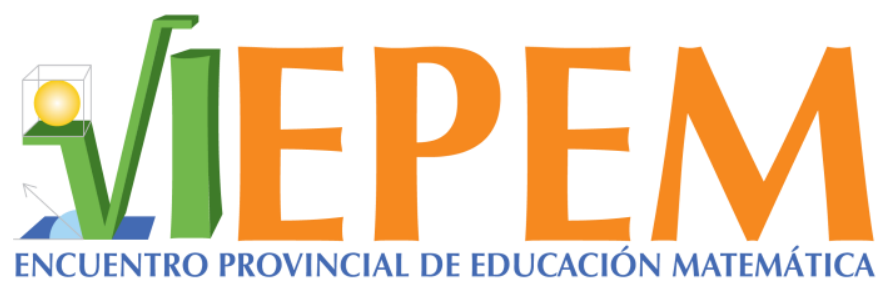

VI Encuentro Provincial de Educación Matemática.

27 al 29 de setiembre, 2017. Puntarenas, Costa Rica.

\title{
Geometría en los Templos de Costa Rica: sugerencias prácticas para abordar la Geometría Euclídea desde la Visión Sociocultural de las Matemáticas
}

\author{
Margot Martínez Rodríguez \\ margot.martinez.rodriguez@una.cr \\ Escuela de Matemática-Universidad Nacional \\ Costa Rica \\ Jesennia Chavarría Vásquez \\ jessenia.chavarria.vasquez@una.cr \\ Escuela de Matemática-Universidad \\ Nacional \\ Costa Rica \\ Marcela García Borbón \\ marcela.garcia.borbon@una.cr \\ División de Educología-Universidad \\ Nacional \\ Costa Rica \\ María Elena Gavarrete Villaverde \\ maria.gavarrette.villaverde@una.cr \\ Escuela de Matemática-Universidad \\ Nacional \\ Costa Rica \\ Gerald Benavides Guido \\ Estudiante \\ gerald.benavides.guido@est.una.cr \\ Escuela de Matemática-Universidad \\ Nacional \\ Costa Rica
}

\begin{abstract}
Resumen
Este taller describe una secuencia de actividades y fundamentos teóricos para la contextualización activa en el desarrollo de la Geometría Euclídea en la Educación Secundaria. Este taller se enmarca dentro del proyecto PPA-017615 Formación Docente bajo la Visión Sociocultural de las Matemáticas, adscrito a la Escuela de Matemática de la Universidad Nacional. El taller tiene como propósito el uso de la visión sociocultural de las
\end{abstract}

Taller

Martínez, M.; Chavarría, J.; García, M.; Gavarrete, M. E. y Benavides, G. (2017). Geometría en los Templos de Costa Rica: sugerencias prácticas para abordar la Geometría Euclídea desde la Visión Sociocultural de las Matemáticas. En Y. Morales-López, M. Picado, R. Gamboa, C. Martínez, M. Castillo y R. Hidalgo (Eds.), Memorias del VI Encuentro Provincial de Educación Matemática, Costa Rica, 2017 (pp. 41-43). Heredia: Universidad Nacional. ISBN: 978-9968-9661-5-3. DOI: http://dx.doi.org/10.15359/epem.6.10 
Geometría en los Templos de Costa Rica: sugerencias prácticas para abordar la Geometría Euclídea desde la Visión Sociocultural de las Matemáticas

matemáticas en la construcción y verificación de propiedades geométricas, en este caso particular, a partir de las estructuras arquitectónicas de algunos templos en Costa Rica. El principal resultado que se espera a partir del taller es la apropiación e integración del conocimiento geométrico por parte de los participantes, a partir de elementos del propio contexto, que conlleve a la elaboración de construcciones geométricas con regla y compás y su constatación haciendo uso del software Geogebra.

Palabras clave: educación matemática, visión sociocultural, etnomatemática, geometría euclídea, contextualización activa.

\section{Introducción}

Uno de los referentes actuales en Educación Matemática, a nivel internacional, es la etnomatemática, la cual ha permeado el nuevo enfoque metodológico de los programas de matemática del Ministerio de Educación Pública de Costa Rica (MEP) para la educación secundaria a través de la contextualización activa (MEP, 2012). La propuesta de este taller es abordar la construcción y verificación de propiedades de la geometría euclídea, desde la visión sociocultural de las matemática (Bishop, 1999; D’Ambrosio, 2008) y a través de las estructuras arquitectónicas de templos religiosos en Costa Rica.

En este taller se abordarán conceptos matemáticos importantes para la comprensión del diseño y la construcción de templos, tales como: arcos, punto medio, segmento tangente, segmento secante, simetría, tipos de simetría, rectas y puntos notables en un triángulo, entre otros.

Por lo tanto, se pretenden realizar construcciones geométricas, a partir del uso de la regla y el compás, de manera que se evidencie su aplicación en la interpretación arquitectónica de templos en Costa Rica, y a su vez permita desarrollar habilidades relacionadas con localización y trazo puntos, ángulos, rectas, así como la resolución de problemas contextualizados relacionados con simetría axial.

\section{Metodología del taller}

La metodología que se utilizará en el taller se basa en tres actividades. Una primera actividad consiste en conocer distintos tipos de arcos e identificarlos en la arquitectura de templos en Costa Rica. Los tipos de arco que se analizarán en el taller son: romano o medio punto, rebajado, arábigo, ojival o equilátero y peraltado o lanceta (Sánchez Sánchez, 2011). Para el desarrollo de esta actividad se entregarán fichas de trabajo con el bosquejo de los tipos de arco e imágenes de diferentes templos.

Una segunda actividad, que constituye el foco central del taller, consiste en la construcción reflexiva de arcos a partir de la Geometría Euclídea. Para el desarrollo de esta actividad se utilizará regla y compás y fichas de trabajo, y se socializarán los resultados entre los participantes.

Finalmente, se desarrollará la construcción dirigida de algunos de los arcos 
Geometría en los Templos de Costa Rica: sugerencias prácticas para abordar la Geometría Euclídea desde la Visión Sociocultural de las Matemáticas

presentados, utilizando la tecnología a través del software Geogebra.

\section{Resultados esperados}

A partir de la vivencia de los participantes en el taller se espera que los docentes innoven en sus prácticas de mediación pedagógica integrando en éstas la matemática del propio contexto, así como el uso de recursos y materiales didácticos tradicionales y tecnológicos.

Asimismo, se espera que los docentes se empoderen del contexto sociocultural en el que desarrollan su labor docente para facilitar el conocimiento geométrico y en general, el conocimiento cultural y matemático.

\section{Referencias}

Bischop, A.J. (1999). Enculturación Matemática. Barcelona: Paidós.

D’Ambrosio, U. (2008). Etnomatemática - Eslabón entre las tradiciones y la modernidad. México: Limusa.

Ministerio de Educación Pública (2012). Programas de Estudio de Matemática, Reforma Curricular en Ética, Estética y Ciudadanía. San José: Ministerio de Educación Pública.

Sánchez Sánchez, N. (2011). Geometría de los arcos : guía para la construcción y trazado de $\quad$ arcos, $130 . \quad$ Recuperado de http://www.carm.es/web/pagina?IDCONTENIDO=8495\&IDTIPO=246\&RASTRO= c943\$m4331,4330

\section{@ $\odot \Theta \Theta$}

Esta obra está bajo una licencia de Creative Commons Reconocimiento-NoComercialSinObraDerivada 4.0 Internacional. 